\title{
Pulsed wave-doppler ultrasonographic evaluation of mammary blood flow speed in cows during different productive periods
}

\author{
Giuseppe Piccione ${ }^{1}$, Amaranta Arcigli ${ }^{1}$, Francesco Fazio ${ }^{2}$, Elisabetta Giudice ${ }^{3}$ \& Giovanni Caola ${ }^{1}$
}

\begin{abstract}
Circulatory phenomena are complex organic functions that depend on several factors as blood viscosity, vascular walls elasticity, cardiac pump rhythm, discontinuous activity, various resistance to blood flow in tissues and spontaneous or induced vasomotor responses. Doppler ultrasonographic method is a valid tool for performing mammary blood flow recordings. Seven Bruna Italiana cows (average age 5 years) during 3 different period of lactation (40, 100, 210 days after the delivery) and during the dry period (290 days after the delivery) were used for our study. Systolic and diastolic flow speeds recordings of right and left external pudendal arteries (before the cranial and the caudal mammary bifurcation) were carried out on each subjects by means of a Pulsed Doppler System. By appliyng repeated measures ANOVA between the different lactation phases and the dry period systolic and diastolic blood flows both for right and left external pudendal artery showed the same pattern. The systolic speed of right and left external pudendal arteries showed the following statistical significances: systolic speed before milking $\left(\mathrm{F}_{(3,18)}=37.71 ; \mathrm{P}<0.0001\right.$, right artery morning; $\mathrm{F}_{(3,18)}=30.91 ; \mathrm{P}<0.0001$, left artery morning; $\mathrm{F}_{(3,18)}=52.94 ; \mathrm{P}<0.0001$, right artery afternoon; $\mathrm{F}_{(3,18)}=32.49 ; \mathrm{P}<0.0001$, left artery afternoon); diastolic speed before milking $\left(\mathrm{F}_{(3,18)}=19.89 ; \mathrm{P}<0.0001\right.$, right artery morning; $\mathrm{F}_{(3,18)}=24.09 ; \mathrm{P}<0.0001$, left artery morning; $\mathrm{F}_{(3,18)}=36.75 ; \mathrm{P}<0.0001$, right artery afternoon; $\mathrm{F}_{(3,18)}=41.56 ; \mathrm{P}<0.0001$, left artery afternoon). No statistical significant differences were found after milking both in morning and in afternoon for the different lactation phases and the dry period. The obtained results give a contribution to the physiologic knowledges of the cow mammary activity and led us to better understand the complex vascular phenomena during the different lactation and dry periods.
\end{abstract}

Key words: pulsed doppler, systolic speed, diastolic speed, lactation, dry period, cow.

${ }^{1}$ Department of Morphology, Biochemistry, Physiology and Animal Productions (DMBPAP), Faculty of Veterinary Medicine, University of Messina, Messina, Italy. ${ }^{2} \mathrm{PhD}$ student in Equine Physiology, DMBPAP. ${ }^{3}$ Department of Medical Science. CORRESPONDENCE: G. Piccione [Giuseppe.Piccione@unime.it ; Fax: +3990356195]. 


\section{INTRODUCTION}

It is known that the physiological state alteration of the mammary gland are associated to mammary blood flow changes. Uptake of nutrients across the gland is a product of blood flow and arterial-venous difference. Therefore, accurate measurement of mammary blood flow is a requirement for assessing mammary uptake of nutrients and hormones [10].

Although the obviousness of the circulation's transport function importance, little is known on the regulation mechanisms of blood flow rate to the mammary gland; however, a close relationship between mammary blood flow and gland metabolic activity seems to be present $[4,9]$. Thus, any factor which alters mammary blood flow may affect milk secretion by changing the gland's supply of oxygen and milk precursors [14].

With the aim to provide information on the mammary gland functional conditions during lactation in ruminants, several investigations have been carried out on vascular flows $[8,10,15,18]$. Circulatory phenomena are complex organic functions that depend on several factors as blood viscosity, vascular walls elasticity, cardiac pump rhythm, discontinuous activity, various resistance to blood flow in tissues and spontaneous or induced vasomotor responses [5].

Doppler ultrasonographic method, as described by Drost in1978 [7], is a valid tool for performing mammary blood flow recordings; it is based on transit ultrasounds and because the probe is not surgically applied to the examined blood vessel this technique is different from present-day methods e.g. thermodilution and electromagnetic flowmeter [8].

On the basis of this knowledge, we investigated mammary blood flow by means of a pulsed waveDoppler ultrasonographic technique.

\section{MATERIALS AND METHODS}

Seven Bruna Italiana cows (average age 5 years), clinically healthy and in good nutritional conditions, during 3 different period of lactation (40, 100, 210 days after the delivery) and during the dry period (290 days after the delivery) were used for our study. Mean milk production was: 25 1/day 40 days after the delivery; 22 1/day 100 days after the delivery and 15 1/day 210 days after the delivery. The animals were stabled in the same breeding and were fed on unifeed diet adapted to the different lactation and dry periods, with free access to water.
Animals were milked twice a day (at 7 a.m. and at 5 p.m.) by means of a milking machine ${ }^{1}$.On all subjects of systolic and diastolic flow speeds recordings of right and left external pudendal arteries (before of the cranial and caudal mammary bifurcation) were carried out by means of a Pulsed Doppler System ${ }^{2}$ (PW-mode, $8 \mathrm{MHz}$ probe, $50 \%$ gain, 7.5 power and $10 \mathrm{~mm}$ depth).

The probe was placed on the blood vessel to clearly visualise blood flow. Recordings were carried out on conscious standing cows at 40,100,210, 290 days from the delivery, before and after the morning and afternoon milkings. Seven days prior to each recording, animals underwent an adaptation period and they were handled with a Doppler equipment and heart rate recordings were carried out in order to evaluate a potential stressful situation. During the vascular flow speeds recordings, heart rate was between 60 and 70 beats/min (physiological values for this species) [1].

In order to reduce as much as possible the examination bias, handlings during the adaptation periods and recordings were done by the same well experienced operator. Since intragroup variance showed no statistical differences, statistical analysis was carried out on mean values of the recorded parameters and on these values we applied the analysis of variance (repeated measures ANOVA), as to evaluate the statistical significant differences obtained by comparing systolic and diastolic speeds recorded during the first, the second, and the third phase of lactation before morning and afternoon milking and the dry period.

Furhtermore systolic and diastolic speeds recorded during the first, the second, and the third phase of lactation after morning and afternoon milking were also compared. All work presented here complies with current regulation covering animal experimentation in Italy.

\section{RESULTS}

Figures 1 and 2 show systolic and diastolic speeds of the right and left external pudendal arteries with their statistical significances in 7 Bruna Italiana cows before and after milking (a: morning; $b$ : afternoon) and during the dry period.

By appliyng repeated measures ANOVA between the different lactation phases and the dry period 
systolic and diastolic blood flows both for right and left external pudendal artery showed the same pattern.

The systolic speed of the right and left external pudendal arteries showed the following statistical significances: systolic speed before milking $\left(\mathrm{F}_{(3,18)}=37.71 ; \mathrm{P}<0.0001\right.$, right artery morning; $\mathrm{F}_{(3,18)}=30.91 ; \mathrm{P}<0.0001$, left artery morning; $\mathrm{F}_{(3,18)}=$ 52.94; $\mathrm{P}<0.0001$, right artery afternoon; $\mathrm{F}_{(3,18)}=32.49$; $\mathrm{P}<0.0001$, left artery afternoon); diastolic speed before milking $\left(\mathrm{F}_{(3,18)}=19.89 ; \mathrm{P}<0.0001\right.$, right artery morning; $\mathrm{F}_{(3,18)}=24.09 ; \mathrm{P}<0.0001$, left artery morning; $\mathrm{F}_{(3,18)}=36.75 ; \mathrm{P}<0.0001$, right artery afternoon; $\mathrm{F}_{(3,18)}=41.56 ; \mathrm{P}<0.0001$, left artery afternoon). No statistical significant differences were found after milking both in morning and in afternoon for the different lactation phases and dry period.

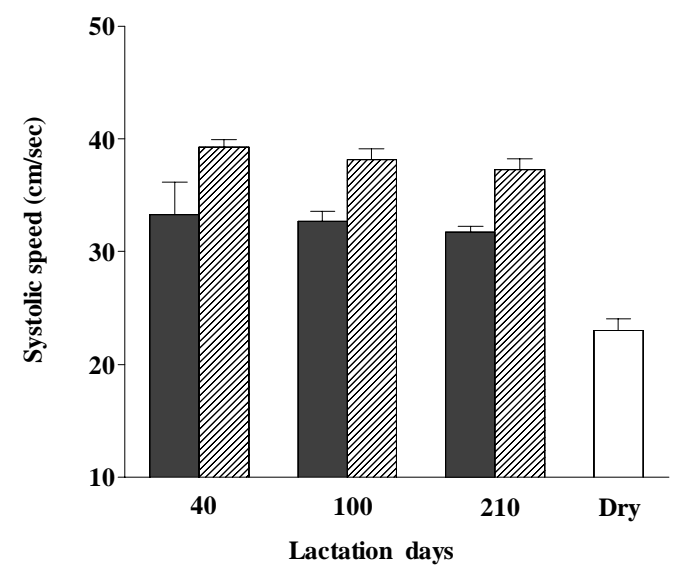

(a)
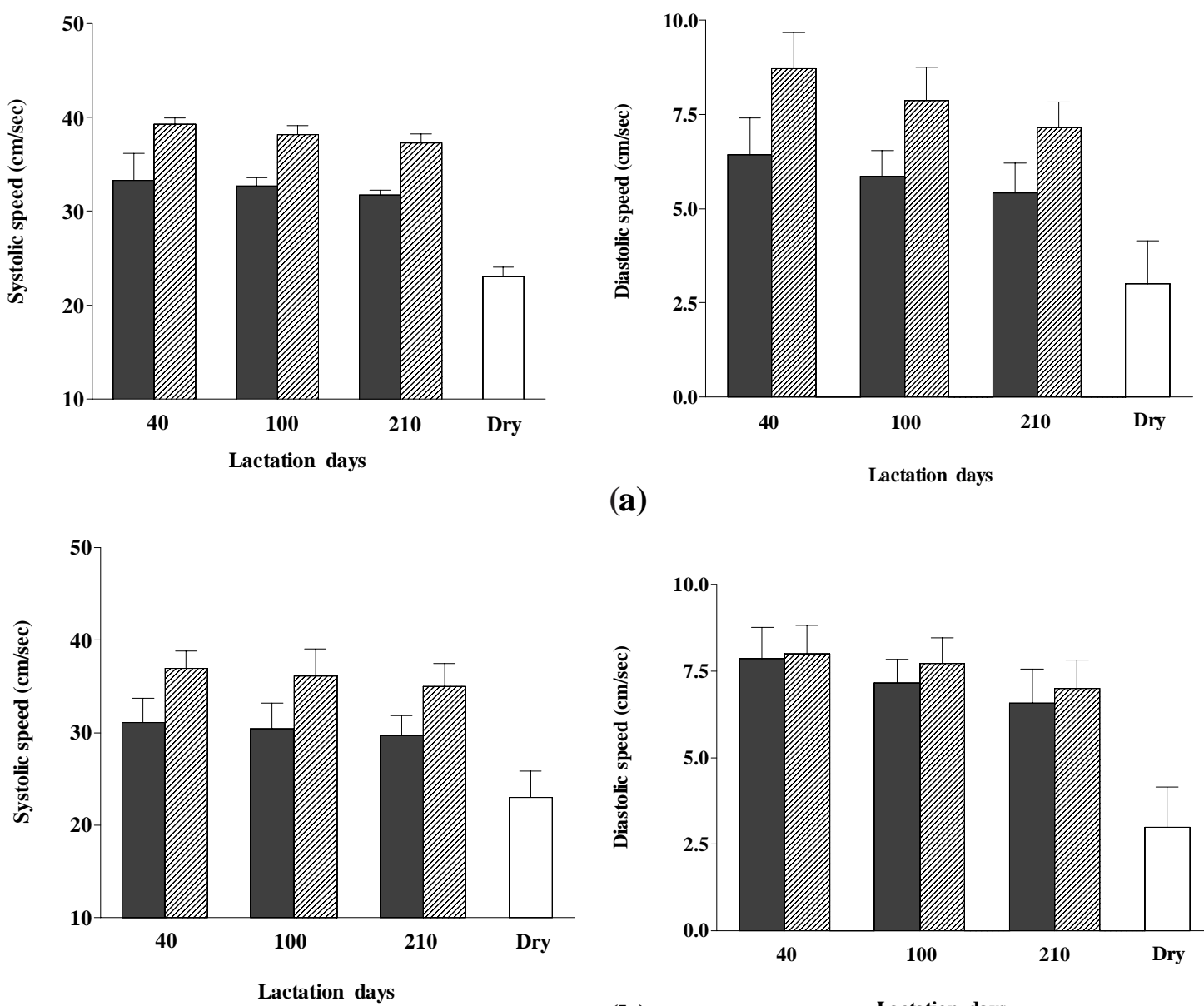

(b)

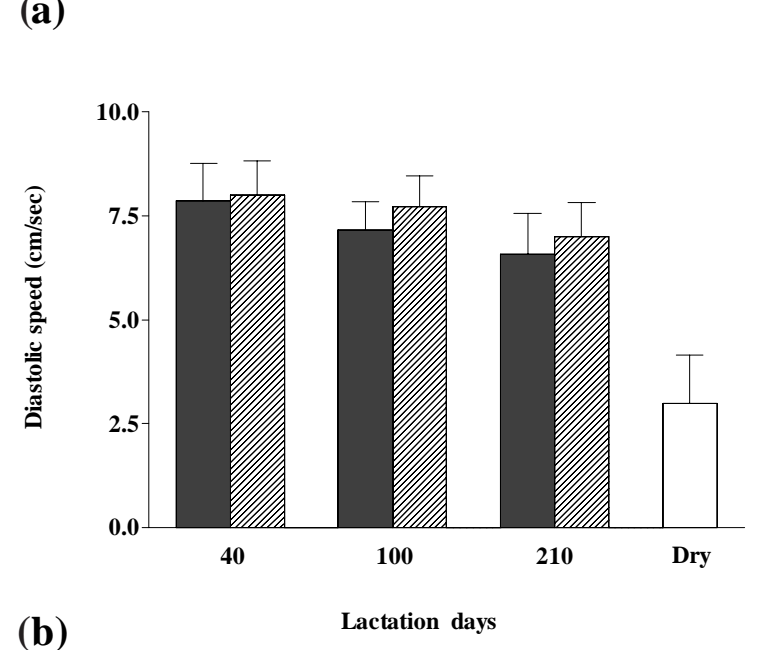

Before milking

[IIIIT After milking

\section{DISCUSSION}

Analysis of the result showed a statistical significant decrease of systolic and diastolic speed of the external pudendal artery (right and left) during the dry period and the different lactation periods. Particularly, these results, closely related to the mammary functionality could be correlated with the well-known inverse linear relationship among the mammary blood flow and the intramammary pressure [14]. Furthermore, a decrease in intramammary pressure at the beginning of lactation may be responsible for the postpartum mammary blood flow increase [16].

Mammary blood flow thus increases markedly at the onset of lactation, where also milk synthesis

Figure 1. Right external pudendal artery systolic and diastolic speeds with their statistical significances in 7 Bruna Italiana cows before and after milking (a: morning; b: afternoon) and during the dry period. Significant differences: * $v s$ Dry P<0.001 

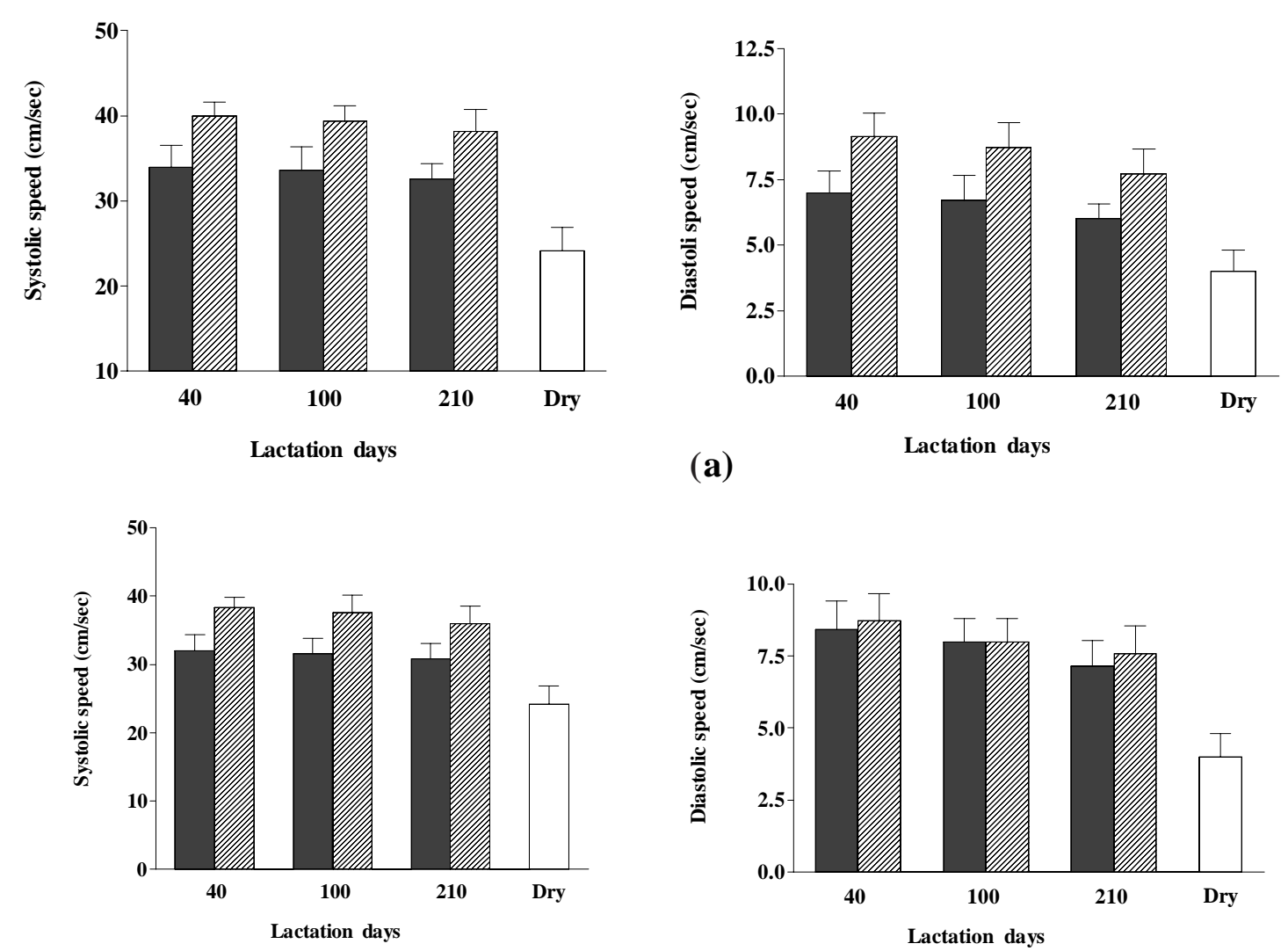

(b)

Figure 2. Left external pudendal artery systolic and diastolic speeds with their statistical significances in 7 Bruna Italiana cows before and after milking (a: morning; b: afternoon) and during the dry period. Significant differences: * vs Dry P<0.001

and nutrient requirement of the mammary gland is increased [12]. Intramammary pressure increase is a very important factor for the milk production. Between 2 and 5 hours after milking, the milk is stored in little ducts and then in great ducts. During this period, intramammary pressure increase proportionally to the milk production. Between 5 and 8 hours after milking the smooth muscle fibrocells are relaxed and milk is stored in the cistern. During this phase intramammary pressure increase less respectively to milk production to help the best refilling of the gland. Afterwards the pressure increase again and the milk production slows down till stop 24-72 hours after milking [17]. In dry animals, the lower mammary blood flow values recorded can be explained in terms of gland inactivity and physiological peculiarity [15]. Fasting [2,3] and acute cold [13] or other stress [11,19] on the other hand has a depressing effect on mammary blood flow and milk yield. Mammary blood flow is an important determining factor for nutrient supply to the mammary gland, and it is generally established that there is a fairly close correlation between mammary blood flow and milk production in goats and cows $[6,12]$. Whether mammary blood flow is mainly determined by mammary metabolic activity, or if rate of mammary blood flow also has a more direct influence on mammary metabolism is still an unresolved question. The reason for the close correlation between mammary blood flow and milk yield, and the precise role of mammary blood flow in the regulation of milk synthesis is therefore not yet understood. It is still only poorly known how mammary blood flow is regulated, and whether the mammary metabolism influences mammary blood flow or vice versa. 


\section{CONCLUSION}

The obtained results give a contribution to the physiologic knowledges of the cow mammary activity and led us to better understand the complex vascular phenomena during the different lactation and dry periods.

\section{Sources and Manufacturers}

${ }^{1}$ Milking machine. Model PVU 37L, Milkline. Podenzano (PC). Italy.

${ }^{2}$ Pulsed Doppler System. DLW Elektronische Systeme Gmbh Sipplingen. Germany.

\section{REFERENCES}

1 Aguggini G., Beghelli V., Clement M.G., D'Angelo A., Debenedetti A., Facello C., Giulio L.F., Guglielmino R., Lucaroni A., Maffeo G., Marongini A., Naitana S., Nuvoli P. \& Piazza R. 1997. Lattazione. In: Fisiologia degli animali domestici con elementi di etologia. Torino: Unione Tipografico-Editrice Torinese, pp.807-840.

2 Annison E.F., Linzell J.L. \& West C.E. 1968. Mammary and whole animal metabolism of glucose and fatty acids in fasting lactatig goats. Journal of Physiology. 197: 445-459.

3 Chaiyabutr N., Faulkner A. \& Peaker M. 1980. Effects of starvation on the cardiovascular system, water balance and milk secretion in lactating goats. Research Veterinary Science. 28: 291-295.

4 Chatwin A.L., Linzell J.L. \& Setchell B.P. 1969. Cardiovascular changes during lactation in the rat. Journal of Endocrinology. 44: 247-251.

5 Dauzat M. 1988. Applicazione dell'effetto doppler alla misurazione della velocità del sangue. In: Ultrasonografia vascolare . Padova: Piccin Nuova Libraria, pp. 5-6.

6 Davis S.R. \& Collier R.J. 1985. Mammary blood flow and regulation of substrate supply for milk synthesis. Journal Dairy Science. 68: 1041-1058.

7 Drost C.J. 1978. Vessel diameter-independent volume flow measurements using ultrasound. In: Proceedings of the 17th San Diego Biomedical Symposium. (San Diego, U.S.A.). p.299.

8 Gorewit R.C., Aromando M.C. \& Bristol D.G. 1989. Measuring bovine mammary gland flow using a transit time ultrasonic flow probe. Journal of Dairy Science. 72: 1918-1928

9 Hardwick D.C. \& Linzell J.L. 1960. Some factors affecting milk secretion by the isolated perfused mammary gland. Journal of Physiology. 154: 547-552.

10 Kensinger M.H., Collier R.J, Wilcox C.J. \& Caton D. 1983. Variability of resting mammary blood flow in non lactating Holstein cows. Journal of Dairy Science. 66: 1742-1746.

11 Linzell J.L. 1960. Mammary gland blood flow and oxygen, glucose and volatile fatty acid uptake in the conscious goat. Journal of Physiology. 153: 492-499.

12 Linzell J.L. 1974. Mammary blood flow and methods of identifying and measuring precursors of milk. In: Lactation-A Comprehensive Treatise. New York: Academic Press, pp. 143-225.

13 Lough D.S., Beede D.L. \& Wilcox C.J. 1990. Effects of feed intake and thermal stress on mammary blood flow and other physiological measurements in lactating dairy cows. Journal of Dairy Science. 73: 325-332.

14 Pearl S.L., Downey H.F. \& Lepper T.L. 1973. Intramammary pressure and mammary blood flow in lactating goats. Journal of Physiology. 283:1319-1323.

15 Piccione G., Arcigli A., Assenza A., Percipalle M. \& Caola G. 2004. Pulsed wave-doppler ultrasonographic evaluation of the mammary blood flow speed in sheep. Acta Veterinary Brno. 72: 69-73.

16 Reynolds M. 1969. Relationship of mammary circulation and oxygen consumption to lactogenesis. In: Reynolds M. \& Folley S.J. (Eds). Lactogenesis: the initiation of milk secretion at parturition. Philadelphia: University of Pensylvania Press, pp.145-151.

17 Succi G. \& Hoffmann I. 1997. La vacca da latte. Milano: CittàStudi, pp.165-224.

18 Thivierge M.C., Petitclerc D., Bernier J.F., Couture Y. \& Lapierre H. 2000. External pudic venous reflux into mammary vein in lactating dairy cows. Journal of Dairy Science. 83: 2230-2238.

19 Thompson G.E. \& Thomson E.M. 1972. Effect of cold exposure on mammary circulation, oxygen, consumption and milk secretion in the goat. Journal of Physiology. 272: 187-196. 